\title{
Effect of treatment on urinary kidney injury molecule-1 in IgA nephropathy
}

\author{
Mi Seon Seo ${ }^{1}$, Moo Yong Park ${ }^{3}$, Soo Jeong Choi ${ }^{3}$, Jin Seok Jeon ${ }^{1,2}$, Hyunjin Noh ${ }^{1,2}$, Jin Kuk Kim³, \\ Dong Cheol Han ${ }^{1,2}$, Seung Duk Hwang ${ }^{3}$, So Young Jin ${ }^{4}$ and Soon Hyo Kwon ${ }^{1,2^{*}}$
}

\begin{abstract}
Background: Kidney injury molecule-1 (KIM-1) is a biomarker useful for detecting early tubular damage and has been recently reported as a useful marker for evaluating kidney injury in IgA nephropathy (IgAN). We therefore investigated whether treatment decreases urinary KIM-1 excretion in IgAN.
\end{abstract}

Methods: We prospectively enrolled 37 patients with biopsy-proven IgAN. Urinary KIM-1 was assessed before and after treatment, which included low salt diet, blood pressure control, pharmacotherapy with angiotensin receptor blockers and/or angiotensin converting enzyme inhibitors, and immunosuppressive agents as necessary. The median treatment duration was 24 months.

Results: Urinary KIM-1/creatinine ( $\mathrm{Cr}$ ) was significantly decreased in patients with IgAN after treatment compared to baseline $(P<0.0001,1.16[0.51-1.83]$ vs $0.26[0.12-0.65] \mathrm{ng} / \mathrm{mg})$. There was a decrease in the amount of proteinuria after treatment, but it was not statistically significant ( $P=0.052,748.1$ [405-1569.7] vs $569.2[252.2-1114] \mathrm{g} / \mathrm{d})$. Estimated glomerular filtration rate (eGFR) did not change with treatment ( $P=0.599,79.28 \pm 30.56$ vs $80.98 \pm 32.37 \mathrm{ml} / \mathrm{min} /$ $1.73 \mathrm{~m}^{2}$ ). Urinary KIM-1 was not correlated with proteinuria baseline or follow up (pre-: $R=-0.100, P=0.577$, post-: $R=0.001, P=0.993$ ). In patients with higher baseline urinary KIM-1, both urinary KIM-1 level and proteinuria were significantly decreased following treatment.

Conclusions: Treatment decreases urinary KIM-1/Cr in patients with IgAN. It also reduces proteinuria in patients with higher baseline urinary KIM-1. These results suggest a potential role for urinary KIM-1 as a biomarker for predicting treatment response in IgAN, however, further study is needed to verify this.

Keywords: Biomarker, IgA nephropathy, KIM-1, Treatment in IgA nephropathy reduced the urinary KIM-1 excretion

\section{Background}

IgA nephropathy (IgAN) is the most common glomerulonephritis in the world, accounting for $20-45 \%$ of primary glomerular disease $[1,2]$. Long-term studies report that up to $30 \%$ of patients with IgAN progress to end-stage renal disease (ESRD) within twenty years [3-5]. Hypertension, massive proteinuria, elevated serum creatinine concentration, glomerular sclerosis, and interstitial fibrosis are predictors of poor renal outcome in IgAN $[4,5]$. However, these prognostic indicators have low sensitivity and

\footnotetext{
* Correspondence: ksoonhyo@schmc.ac.kr

'Division of Nephrology, Seoul, South Korea

${ }^{2}$ Hyonam Kidney Laboratory, Soon Chun Hyang University Hospital, Seoul, South Korea

Full list of author information is available at the end of the article
}

specificity [6]. More accurate prognostic markers are required to predict the progress of IgAN and determine treatment.

Kidney injury molecule-1 (KIM-1) is a sensitive marker for detecting the presence of tubular damage [7-10]. KIM1 expression is significantly induced in various primary and secondary kidney diseases and in allograft nephropathy [9-11]. Tubular KIM-1 expression is significantly associated with tubulointerstitial injury and inflammation, and increased urinary KIM-1 levels are strongly related to tubular KIM-1 expression $[8,10,11]$. Therefore, urinary KIM-1 is a valuable biomarker for the existence of tubulointerstitial damage.

Recent studies have shown that in patients with IgAN, urinary KIM-1 is closely associated with disease severity

\section{Biomed Central}

(C) 2013 Seo et al.; licensee BioMed Central Ltd. This is an Open Access article distributed under the terms of the Creative Commons Attribution License (http://creativecommons.org/licenses/by/2.0), which permits unrestricted use, distribution, and reproduction in any medium, provided the original work is properly cited. 
and is an independent predictor of ESRD [12,13]. However, it is still unclear whether urinary KIM-1 levels are affected by treatment. In the current study, we investigated whether urinary excretion of KIM-1 changes after treatment in patients with IgAN. We then further analyzed the relationship between urinary KIM-1 level and proteinuria.

\section{Methods}

\section{Patients and methods}

For the present study, prospective patients with biopsyproven IgAN were enrolled from January 2009 at Soon Chun Hyang University Seoul and Bucheon Hospital. Study protocols were reviewed and approved by the Soon Chun Hyang University Seoul Hospital Institutional Review Board and Soon Chun Hyang University Bucheon Hospital Institutional Review Board, and written informed consent was obtained from each patient before enrollment. A diagnosis of IgAN was defined as the predominant mesangial deposition of IgA. Clinical and laboratory data were collected at the time of biopsy. Urinary samples were centrifuged at $3000 \mathrm{rpm}$ for $10 \mathrm{~min}$ to remove cellular components, and the supernatant was frozen at $-70^{\circ} \mathrm{C}$ until use. Urinary KIM-1 excretion was measured at diagnosis. Urinary KIM-1 was then measured at follow-up after about 2 years of treatment that included a low salt diet, blood pressure control, pharmacotherapy with angiotensin receptor blockers and/ or angiotensin converting enzyme inhibitors, and immunosuppressive agents as necessary. All patients were treated with angiotensin receptor blockers (ARB) and/or angiotensin converting enzyme inhibitors (ACEi). Steroid pulse therapy and oral prednisolone was administered to patients with sustained massive protein excretion exceeding $2 \mathrm{~g} /$ day. Patients with other causes of IgA-positive glomerular staining (systemic lupus erythematosus, Henoch-Schönlein purpura, or liver disease) were excluded from the analysis.

\section{Detection of urinary KIM-1 by enzyme-linked immunossorbent assay}

ELISA was performed in duplicate using a commercial kit (R\&D System, MN, USA) in accordance with the manufacturer's guidelines to measure KIM-1 protein levels in the urine. Inter- and intra-assay variability was $<10 \%$. To adjust urinary KIM-1 levels, urinary creatinine was also measured for each urine specimen. Adjusted urinary KIM-1 was expressed as urinary KIM-1concentration/creatinine concentration (ng/mg Cr). All KIM-1 levels in this study are expressed in this way. Reference values for urinary KIM-1/creatinine were obtained from urine measurements in 27 healthy volunteers who were all unmatched Korean men and women. Mean urinary KIM-1 excretion was $0.18 \mathrm{ng} / \mathrm{mg}$ with a $95 \%$ confidence interval (CI) of
0.096 to $0.27 \mathrm{ng} / \mathrm{mg}$. The cutoff value for normal $(0.27 \mathrm{ng} / \mathrm{mg})$ was based on the upper limit of the $95 \%$ CI. The urinary KIM- 1 of IgAN patients increased compared to that of normal volunteers [14].

\section{Grading of tubular atrophy/interstitial fibrosis}

Grading of tubular atrophy/interstitial fibrosis followed the Oxford classification system, in which grading is determined by the percentage of cortical area involved by tubular atrophy or interstitial fibrosis, whichever is greater (tubular atrophy/interstitial fibrosis 0: 0-25\%, tubular atrophy/interstitial fibrosis 1: $26-50 \%$, tubular atrophy/interstitial fibrosis 2: > 50\%) [15].

\section{Statistical analyses}

Data are expressed as mean \pm standard deviation or as median with interquartile range. Differences in quantitative data were evaluated using a paired $t$-test. Differences in qualitative data were evaluated using a chi-square test. When a normal distribution was present, ANOVA with a post hoc test or paired $t$-test were used. When an abnormal distribution was present, the nonparametric Kruskal-Wallis and Wilcoxon signed rank tests were used. Correlations between urinary KIM-1 and clinical parameters were determined using the Pearson correlation coefficient. P-values of $<0.05$ were considered statistically significant. Statistical analysis was performed using SPSS for Windows software version 14.0 (SPSS Inc., Chicago, IL, USA).

\section{Results}

Clinical and histopathological characteristics of patients with IgAN

Thirty-seven patients with IgAN were studied. Patient characteristics at baseline are presented in Table 1.

\begin{tabular}{ll} 
Table 1 Patient characteristics at baseline \\
\hline Characteristic \\
\hline Age (years) \\
Male/Female (n)\{\%\} \\
Serum Creatinine (mg/dL) & $18 / 19\{48.6 / 51.4\}$ \\
CKD EPI eGFR (ml/min/1.73 m²) & $1.24 \pm 0.68$ \\
24 hr Urinary Protein (mg/day) & $79.28 \pm 30.56$ \\
Mean Blood Pressure, systolic (mmHg) & $748.1[405-1569.7]$ \\
Mean Blood Pressure, diastolic (mmHg) & $125.4 \pm 13.8$ \\
Mesagial hypercellularity (\%) & $78.1 \pm 8.7$ \\
Segmental glomerulosclerosis (\%) & 64.8 \\
Endocapillary hypercellularity (\%) & 91.8 \\
Tubular atrophy/interstitial fibrosis 1 (\%) & 37.8 \\
Tubular atrophy/interstitial fibrosis 2 (\%) & 32.4 \\
\hline
\end{tabular}

${ }^{\mathrm{a}}$ Data are expressed as mean $\pm \mathrm{SD}$ or median with interquartile range. 
Table 2 Clinical characteristics according to treatment modality ${ }^{a}$

\begin{tabular}{|c|c|c|c|}
\hline Variable & Immunotherapy & No imunotherapy & $\mathbf{P}$ \\
\hline Age (years) & $33.6 \pm 18.32$ & $40.06 \pm 10.31$ & 0.481 \\
\hline Male/Female $\{\%\}$ & $4 / 1\{80 / 20\}$ & $15 / 17\{47 / 53\}$ & $<0.0001$ \\
\hline Serum Creatinine (mg/dL) & $1.52 \pm 0.55$ & $1.20 \pm 0.69$ & 0.347 \\
\hline CKD EPI eGFR $\left(\mathrm{ml} / \mathrm{min} / 1.73 \mathrm{~m}^{2}\right)$ & $70.06 \pm 37.03$ & $80.62 \pm 29.90$ & 0.505 \\
\hline 24 hrs Urinary Protein (mg/day) & $4077.18 \pm 3098.19$ & $1000.63 \pm 899.85$ & $<0.0001$ \\
\hline Mean Blood Pressure, systolic (mm/Hg) & $128 \pm 13$ & $125 \pm 14.14$ & 0.693 \\
\hline Mean Blood Pressure, diastolic (mmHg) & $76 \pm 8.3$ & $78 \pm 8.95$ & 0.664 \\
\hline Mesagial hypercellularity (\%) & 100 & 59.4 & $<0.0001$ \\
\hline Segmental glomerularsclerosis (\%) & 100 & 90.7 & $<0.0001$ \\
\hline Endocapillary hypercellularity (\%) & 80 & 31.3 & $<0.0001$ \\
\hline Tubular atrophy/interstitial fibrosis 1 (\%) & 0 & 37.5 & $<0.0001$ \\
\hline Tubular atrophy/interstitial fibrosis 2 (\%) & 60 & 15.7 & $<0.0001$ \\
\hline Baseline KIM-1/Cr (ng/mg) & $0.51[0.31-1.23]$ & $1.12[0.62-2.02]$ & 0.155 \\
\hline Follow-up KIM-1/Cr (ng/mg) & $0.52[0.01-0.64]$ & $0.26[0.13-0.73]$ & 0.625 \\
\hline$\Delta \mathrm{KIM}-1 / \mathrm{Cr}(\mathrm{ng} / \mathrm{mg})$ & $0.49[0.34-0.71]$ & $0.81[0.17-1.23]$ & 0.230 \\
\hline Baseline eGFR $\left(\mathrm{ml} / \mathrm{min} / 1.73 \mathrm{~m}^{2}\right)$ & $70.65 \pm 37.03$ & $80.62 \pm 29.9$ & 0.505 \\
\hline Follow-up eGFR (ml/min/1.73 m²) & $72.82 \pm 48.44^{*}$ & $82.26 \pm 30.03^{* *}$ & 0.552 \\
\hline Baseline proteinuria (mg/d) & $4855.1[1569.7-5560.5]$ & 720 [401-1189.7] & \\
\hline Follow-up proteinuria (mg/d) & $1323.9[374.6-1480]$ & $545.6[250.5-824]$ & \\
\hline$P$ & 0.273 & 0.077 & \\
\hline
\end{tabular}

${ }^{\mathrm{a}}$ Data are expressed as median \pm SD or median with interquartile range. Compared with baseline eGFR: ${ }^{*} \mathrm{P}=0.904 ;{ }^{* *} \mathrm{P}=0.572$.

\section{Treatment}

During follow up, all patients were treated with ACEis and/ or ARBs. Immunosuppressive therapy was initiated in five patients (13.5\%) who either had progressive deterioration of renal function or persistent proteinuria (Table 2). A comparison of the clinical and histopathological characteristics of the patients receiving and not receiving immunosuppressive therapy is shown in Table 2. $24 \mathrm{hr}$ urinary protein was significantly higher in the immunosuppressive therapy group $(\mathrm{P}<0.01,4.07 \pm 3.09$ vs $1.00 \pm 0.89 \mathrm{~g} / \mathrm{d})$. The proportion of patients with mesangial hypercellularity, segmental glomerulosclerosis, endocapillary hypercellularity, and tubular atrophy/interstitial fibrosis 2 was significantly higher in the immunosuppressive therapy group.

\section{Concentration of urinary KIM-1 at baseline and follow-up}

The mean follow up duration was $23.56 \pm 5.08$ months. Baseline urinary KIM-1 was 1.16 [0.51-1.83] ng/mg while the follow-up level was $0.26[0.12-0.65] \mathrm{ng} / \mathrm{mg}$. Urinary KIM-1 was significantly decreased in patients with IgAN after treatment (Figure 1). KIM-1 levels normalized in 19 patients (51.35\%) after treatment.

Clinical parameters of IgAN patients at baseline and follow-up At follow-up, there was a decrease in the amount of proteinuria, but it was not statistically significant $(\mathrm{P}=0.052$,
748.1 [405-1569.7] vs 569.2 [252.2-1114] g/d). Treatment did not affect estimated glomerular filtration rate (eGFR) $\left(\mathrm{P}=0.599,79.28 \pm 30.56\right.$ vs $\left.80.98 \pm 32.37 \mathrm{ml} / \mathrm{min} / 1.73 \mathrm{~m}^{2}\right)$ (Table 3).

Although we found that proteinuria was not significantly reduced after treatment, this was not the case when we analyzed treatment response in patients stratified according to tertiles of baseline urinary KIM-1. After treatment, urinary KIM-1 and proteinuria were significantly decreased in

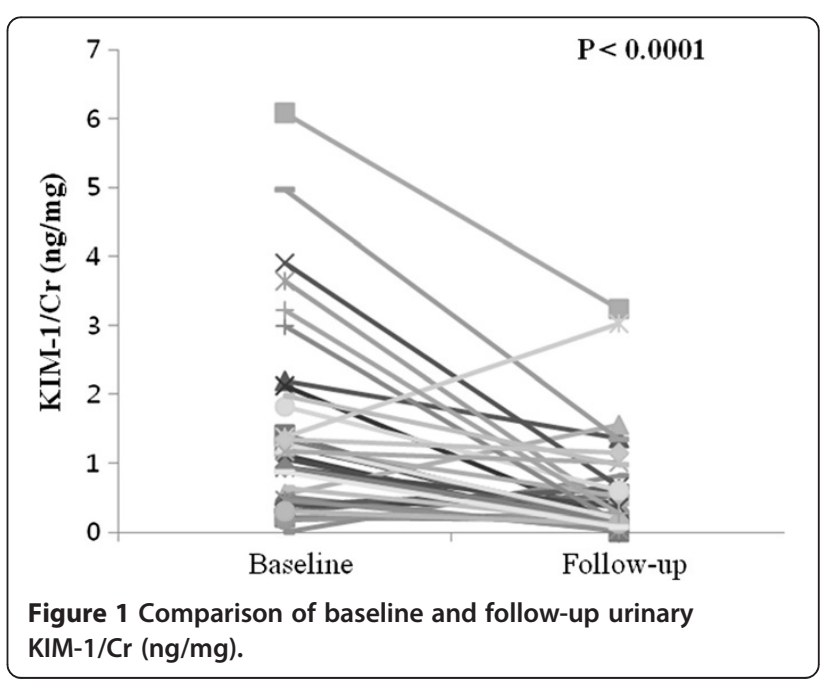


Table 3 Comparison of baseline and follow-up clinical parameters $^{\mathrm{a}}$

\begin{tabular}{lccc}
\hline Variable & Baseline & Follow-up & $\mathbf{P}$ \\
\hline Serum Creatinine $(\mathrm{mg} / \mathrm{dL})$ & $1.0[0.9-1.3]$ & $1.0[0.8-1.3]$ & 0.542 \\
CKD EPI eGFR & $79.28 \pm 30.56$ & $80.98 \pm 32.37$ & 0.599 \\
$\left(\mathrm{ml} / \mathrm{min} / 1.73 \mathrm{~m}^{2}\right)$ & & & \\
SBP $(\mathrm{mmHg})$ & $125 \pm 13.86$ & $119 \pm 15.97$ & 0.050 \\
DBP $(\mathrm{mmHg})$ & $78 \pm 8.76$ & $74 \pm 10.68$ & 0.080 \\
24 hrs Urinary & $748.1[405-1569.7]$ & $569.2[252.2-1114]$ & 0.052 \\
Protein (mg/day) & & & \\
\hline
\end{tabular}

${ }^{a}$ Data are expressed as median \pm SD or median with interquartile range.

patients in the highest tertile (urinary KIM- $1 / \mathrm{Cr}$ : $\mathrm{P}=0.008$, proteinuria: $\mathrm{P}=0.01$ ) (Table 4 ).

When comparing patients whose KIM-1 levels did and did not normalize following treatment, there was no significant decrease of proteinuria or eGFR in either group. There was also no significant difference in follow-up proteinuria or eGFR between the two groups (Table 5). We also compared proteinuria and eGFR between patients who did and did not receive immunosuppressive therapy. There was no significant decrease in proteinuria or eGFR in either group after treatment (Table 2).

Finally, we analyzed proteinuria and eGFR according to reduction of $24 \mathrm{hr}$ urinary protein. There was no significant difference in baseline or follow-up KIM-1 between patients whose $24 \mathrm{hr}$ urinary protein did and did not decrease by more than $50 \%$. However, there was a significant difference in follow-up eGFR between the two groups $(\mathrm{P}=0.04)$ (Table 6).

In our study, baseline urinary KIM-1 was not correlated with renal KIM-1 grade or Oxford classification of renal damage [14].

\section{Association between urinary KIM-1 and proteinuria}

Urinary KIM-1 was not correlated with proteinuria at baseline or follow-up (baseline: $\mathrm{R}=0.100, \mathrm{P}=0.577$, follow-up: $\mathrm{R}=0.001, \mathrm{P}=0.993$ ).

\section{Discussion}

Interstitial kidney damage is a consistent predictor of renal prognosis. Several studies have identified clinical features and histological findings which serve as predictors of adverse renal outcomes. In particular, tubulointerstitial changes have been recognized as important prognostic factors in IgAN [16-19]. However, tubulointerstitial damage is not always associated with proteinuria, which is a marker of glomerular damage [20]. Therefore, it is important to identify a biomarker specific for tubular damage to accurately monitor therapy response and tubular damage in IgAN.

Our data showed that IgAN treatment significantly decreased urinary KIM-1 concentration. This finding suggests that urinary KIM-1 may be a useful biomarker for evaluating and predicting treatment response. Previous studies have found that KIM-1 expression in proximal tubules is associated with interstitial fibrosis and inflammation in various renal diseases $[10,11]$. Several studies have reported that urinary KIM-1 levels are correlated with tubular KIM-1 expression in experimental models and human renal disease [8-10,21]. Because of this, and because it is a non-invasive marker for kidney damage, KIM-1 is a promising biomarker. In IgAN, urinary KIM-1 has clinical implications in predicting renal outcome and assessing tubulointerstitial damage [12,13]. Waanders et al. have reported that urinary KIM-1 levels decreased following antiproteinuric treatment in non-diabetic patients. However, this study included only a small number of IgAN patients $(n=5)$ and had a relatively short follow up duration (6 weeks) [20]. Because IgAN is the most common glomerulonephritis in the world, KIM-1 should be verified as a therapeutic parameter with a long-term study in a large IgAN cohort.

We treated biopsy-proven IgAN patients using conventional methods for 24 months, which resulted in a decrease in KIM-1. We believe there are several possible mechanisms for this result. First, treatment can reverse interstitial damage. All patients were treated with at least one RAS antagonist. One observational human study reported that treatment with an ARB can improve renal interstitial fibrosis. In that study, patients with biopsyproven IgAN and non-IgA mesangioproliferatve glomerulonephritis were treated with an ARB for an average of 28 months. Although the global sclerosis ratio was not significantly altered by treatment with an ARB, 13 of the 15 patients showed decreases in mesangial matrix and

Table 4 Treatment response stratified by baseline urinary KIM-1 level ${ }^{\mathrm{a}}$

\begin{tabular}{cccc}
\hline & $\mathbf{n = 1 3}$ & $\mathbf{n}=\mathbf{1 2}$ & $\mathbf{n = 1 2}$ \\
\hline Baseline KIM-1/Cr (ng/mg) & $0.39[0.3-0.51]$ & $1.19[1.02-1.28]$ & $2.59[1.94-3.7]$ \\
Follow-up KIM-1/Cr (ng/mg) & $0.26[0.12-0.61]$ & $0.17[0.09-0.4]$ & $0.62[0.22-1.35]$ \\
$P$ & 0.91 & 0.002 & 0.008 \\
Baseline proteinuria (mg/d) & $1109[528.2-1639]$ & $537.5[296.9-1453.2]$ & $916.5[508.2-1262.2]$ \\
Follow-up proteinuria (mg/d) & $722.1[252.2-1323.9]$ & $509.5[237.2-979.6]$ & $518.3[361.8-766]$ \\
p & 0.333 & 0.678 & 0.018 \\
\hline
\end{tabular}

${ }^{\mathrm{a}}$ Data are expressed as median with interquartile range. 
Table 5 Baseline and follow-up clinical parameters according to normalization of urinary KIM-1 ${ }^{\text {a }}$

\begin{tabular}{cccc}
\hline & Patients with normalization $(\mathbf{n}=\mathbf{1 9})$ & Patients without normalization $(\mathbf{n}=18)$ & $\mathbf{P}$ \\
\hline Baseline proteinuria $(\mathrm{mg} / \mathrm{d})$ & $718[348.3-1417]$ & $1006.25[537.1-2269.9]$ \\
Follow-up proteinuria $(\mathrm{mg} / \mathrm{d})$ & $522[868.4-1114]^{*}$ & $572.65[270-1260.7]^{* *}$ \\
Baseline eGFR $\left(\mathrm{ml} / \mathrm{min} / 1.73 \mathrm{~m}^{2}\right)$ & $88.6 \pm 36.2$ & $72.6 \pm 29.4$ \\
Follow-up eGFR $\left(\mathrm{ml} / \mathrm{min} / 1.73 \mathrm{~m}^{2}\right)$ & $78.3 \pm 34^{\#}$ & $83.8 \pm 31.2 \&$ & 0.871 \\
\hline
\end{tabular}

${ }^{a}$ Data are expressed as median \pm SD or median with interquartile range. Compared with baseline proteinuria: ${ }^{*} \mathrm{P}=0.925 ;{ }^{* *} \mathrm{P}=0.11$.

Compared with baseline eGFR: ${ }^{*} \mathrm{P}=0.334 ; \& \mathrm{P}=0.141$.

interstitial fibrosis [22]. Kramer at al. showed treatment with an ARB reversed tubular Kim-1 expression in an adriamycin induced nephropathy model [21]. In several other experimental models, ARBs produced renal structural improvement [23-25]. These studies suggest that RAS blockade can improve tubulointerstital damage and decrease urinary Kim-1, a marker of tubular damage. Another explanation for the decreased KIM-1 is that a reduction in proteinuria can lower urinary KIM-1 excretion. A recent study showed that tubular expression of Kim-1 decreased in proportion to decreases in proteinuria as a result of RAAS blockade in adriamycin induced nephropathy and homozygous Ren2rats [21,26]. Another study found proteinuria was able to cause tubulointerstital injury [27]. These studies support the hypothesis that decreased proteinuria reduces proteinuria-induced tubular damage and decreases Kim-1 expression.

A previous study involving patients with various renal diseases showed that even when proteinuria was reduced below a certain threshold (less than $1 \mathrm{~g} / \mathrm{d}$ ), urinary KIM1 did not normalize in 14 of 16 patients [20]. Although our treatment did not profoundly decrease proteinuria, KIM-1 did reach the normal range in $50 \%$ of patients. In patients in the highest tertile for baseline KIM-1, urinary KIM-1 and proteinuria were significantly decreased after treatment. Previous studies reported Kim-1 was not detected in severely damaged tubules $[10,14,21]$. As tubular KIM-1 expression is specific to ongoing tubular cell damage and differentiation [28,29], we hypothesized urinary KIM-1 represented reversibility. In an experimental model, Kim-1 expression was reduced in proportion to proteinuric reduction [21]. This supports the potential of KIM-1 as a biomarker for tubulointerstitial damage and repair.
In our study, treatment reduced urinary KIM-1, but this was not accompanied by a reduction in other clinical parameters. The progression of IgAN is slow, and the response to treatment is also slow. In this study, the follow-up period was relatively short. The proteinuria reduction for all patients did not reach statistical significance, however, it showed a trend in that direction $(\mathrm{p}=0.053)$. The antecedent reduction of urinary KIM1 suggests that urinary KIM-1 may be a more sensitive biomarker and has unique clinical implications in IgAN. KIM-1 has been reported as a better independent prognostic marker than proteinuria for IgAN [12]. Although proteinuria has been considered a main risk factor for decreased kidney function, this is an inconsistent conclusion [6,30,31]. Therefore, long-term studies are needed to evaluate whether treatments targeting KIM-1 can improve outcomes in patients with IgAN.

The correlation between urinary KIM-1 and proteinuria is also inconsistent $[8,10,32]$. Differences in urinary KIM-1 measurement methods may be cause this discrepancy. Preclinical KIM-1 assays should be validated in a large cohort and a variety of clinical settings. Recently, a number of urinary biomarkers have emerged for kidney disease. These urinary biomarkers have the potential to facilitate early diagnosis and management of kidney damage. They may be able to alert clinicians to kidney damage before it can be identified using conventional measurements, such as change in glomerular filtration rate or proteinuria. It is therefore necessary to verify the usefulness of KIM-1 by conducting a longterm study in a large population. This will determine whether treatments targeting KIM-1 can improve outcome in patients with chronic kidney disease.

Table 6 Baseline and follow-up clinical parameters according to reduction in $\mathbf{2 4}$ hr urinary protein ${ }^{\text {a }}$

\begin{tabular}{llll}
\hline Variable & Proteinuria reduction $>\mathbf{5 0 \%}(\mathbf{n}=\mathbf{1 0})$ & Proteinuria reduction $<\mathbf{5 0 \%}(\mathbf{n}=\mathbf{2 6})$ & $\mathbf{P}$ \\
\hline Baseline KIM-1/Cr $(\mathrm{ng} / \mathrm{mg})$ & $1.17[0.44-1.91]$ & $1.16[0.57-1.62]$ & 0.811 \\
Follow-up KIM-1/Cr $(\mathrm{ng} / \mathrm{mg})$ & $0.41[0.21-0.74]$ & $0.19[0.11-0.64]$ & 0.393 \\
Baseline eGFR $\left(\mathrm{ml} / \mathrm{min} / 1.73 \mathrm{~m}^{2}\right)$ & $87.86 \pm 30.34$ & $76.1 \pm 30.59$ & 0.305 \\
Follow-up eGFR $\left(\mathrm{ml} / \mathrm{min} / 1.73 \mathrm{~m}^{2}\right)$ & $98.78 \pm 27.86$ & $74.39 \pm 31.87$ & 0.040 \\
\hline
\end{tabular}

${ }^{\mathrm{a}}$ Data are expressed as median $\pm \mathrm{SD}$ or median with interquartile range. 
This study had several limitations. First, it describes a small number of patients who have well preserved renal function. This population does not represent the various stages of IgAN. Second, the ELISA method used in our study has limited sensitivity. However, the sensitivity was sufficient to investigate the association between urinary KIM-1 and clinical parameters in patients with IgAN. Lastly, because of difficulties in obtaining repeat biopsies, we cannot conclude that decreases in the concentration of urinary KIM-1 improve renal outcomes in IgAN.

\section{Conclusions}

Treatment decreases urinary KIM-1/Cr in patients with IgAN. Urinary KIM-1 does not correlate with proteinuria. Treatment reduced proteinuria in patients in the highest tertile for baseline KIM-1. Future studies should be undertaken to verify the usefulness of KIM-1 as biomarker in IgAN.

\section{Competing interest}

The authors have no competing interests.

\section{Authors' contribution}

KSH was the principal investigator; participated in design and coordination, and helped to draft the manuscript. SMS participated in coordination, wrote the draft manuscript. PMY participated in design and manage the research porject, CSJ participated in design, helped to collect sample and analyzed statistic data. JJS carried measurement of urinary KIM-1. NHJ participated in study design, enrolled patients, and managed samples. HSD, KJK, HDC enrolled patients at clinical office and interpretation of data and drafting and revising the manuscript. JSY made the pathological confirmations of IgAN, reviewed medical records, and participated in data analysis. All authors read and approved the final manuscript.

\section{Acknowledgements}

The authors wish to thank the IgA nephropathy patients in our clinics, You MR at Hyonam Kidney Laboratory for technical assistance and Jang GH at Genome Research Center of Soon Chun Hyang University Bucheon Hospital for acquisition of data. We also thank Mr. Viturawong Charles for kind advice of our manuscript.

\section{Author details}

${ }^{1}$ Division of Nephrology, Seoul, South Korea. ${ }^{2}$ Hyonam Kidney Laboratory, Soon Chun Hyang University Hospital, Seoul, South Korea. ${ }^{3}$ Division of Nephrology, Soon Chun Hyang University Hospital, Bucheon, Korea. ${ }^{4}$ Department of Pathology, Soon Chun Hyang University Hospital, Seoul, South Korea.

Received: 8 November 2012 Accepted: 8 July 2013

Published: 9 July 2013

\section{References}

1. Donadio JV, Grande JP: IgA nephropathy. N Engl J Med 2002, 347(10):738-748.

2. Li LS, Liu ZH: Epidemiologic data of renal diseases from a single unit in China: analysis based on 13,519 renal biopsies. Kidney Int 2004, 66(3):920-923.

3. D'Amico G: Clinical features and natural history in adults with $\lg A$ nephropathy. Am J Kidney Dis 1988, 12(5):353-357.

4. Frimat L, Briancon S, Hestin D, Aymard B, Renoult E, Huu TC, Kessler M: IgA nephropathy: prognostic classification of end-stage renal failure. L'Association des Nephrologues de I'Est. Nephrol Dial Transplant Offic Publ Eur Dial Transpl Assoc Eur Renal Assoc 1997, 12(12):2569-2575.

5. Radford MG Jr, Donadio JV Jr, Bergstralh EJ, Grande JP: Predicting renal outcome in IgA nephropathy. J Am Soc Nephrol 1997, 8(2):199-207.
6. Bartosik LP, Lajoie G, Sugar L, Cattran DC: Predicting progression in IgA nephropathy. Am J Kidney Dis 2001, 38(4):728-735.

7. Han WK, Bailly V, Abichandani R, Thadhani R, Bonventre JV: Kidney Injury Molecule-1 (KIM-1): a novel biomarker for human renal proximal tubule injury. Kidney Int 2002, 62(1):237-244.

8. Vaidya VS, Ramirez V, Ichimura T, Bobadilla NA, Bonventre JV: Urinary kidney injury molecule-1: a sensitive quantitative biomarker for early detection of kidney tubular injury. Am J Physiol Renal Physiol 2006, 290(2):F517-F529.

9. van Timmeren MM, Bakker SJ, Vaidya VS, Bailly V, Schuurs TA, Damman J, Stegeman CA, Bonventre JV, van Goor H: Tubular kidney injury molecule-1 in protein-overload nephropathy. Am J Physiol Renal Physiol 2006, 291(2):F456-F464.

10. van Timmeren MM, van den Heuvel MC, Bailly V, Bakker SJ, van Goor H, Stegeman CA: Tubular kidney injury molecule-1 (KIM-1) in human renal disease. J Pathol 2007, 212(2):209-217.

11. van Timmeren MM, Vaidya VS, van Ree RM, Oterdoom LH, de Vries AP, Gans $\mathrm{RO}$, van Goor H, Stegeman CA, Bonventre JV, Bakker SJ: High urinary excretion of kidney injury molecule- 1 is an independent predictor of graft loss in renal transplant recipients. Transplantation 2007, 84(12):1625-1630.

12. Peters HP, Waanders F, Meijer E, van den Brand J, Steenbergen EJ, van Goor H, Wetzels JF: High urinary excretion of kidney injury molecule- 1 is an independent predictor of end-stage renal disease in patients with IgA nephropathy. Nephrol Dial Transpl Offic Publ Eur Dial Transpl Assoc Eur Renal Assoc 2011, 26(11):3581-3588.

13. Xu PC, Zhang JJ, Chen M, LV JC, Liu G, Zou WZ, Zhang H, Zhao MH: Urinary kidney injury molecule- 1 in patients with $\lg A$ nephropathy is closely associated with disease severity. Nephrol Dial Transplant Offic Publ Eur Dial Transpl Assoc Eur Renal Assoc 2011, 26(10):3229-3236.

14. Kwon SH, Park MY, Jeon JS, Noh H, Choi SJ, Kim JK, Hwang SD, Jin SY, Han DC: KIM-1 expression predicts renal outcomes in IgA nephropathy. Clin Exp Nephrol 2013, 17(3):359-364. doi:10.1007/s10157-012-0707-2

15. Working Group of the International Ig ANN, the Renal Pathology S, Cattran DC, Coppo R, Cook HT, Feehally J, Roberts IS, Troyanov S, Alpers CE, Amore A, et al: The Oxford classification of IgA nephropathy: rationale, clinicopathological correlations, and classification. Kidney Int 2009, 76(5):534-545.

16. Edstrom Halling S, Soderberg MP, Berg UB: Predictors of outcome in paediatric IgA nephropathy with regard to clinical and histopathological variables (Oxford classification). Nephrol Dial Transplant Offic Publ Eur Dial Transpl Assoc Eur Renal Assoc 2012, 27(2):715-722.

17. Walsh M, Sar A, Lee D, Yilmaz S, Benediktsson H, Manns B, Hemmelgarn B: Histopathologic features aid in predicting risk for progression of $\lg A$ nephropathy. Clin J Am Soc Nephrol 2010, 5(3):425-430.

18. Roberts IS, Cook HT, Troyanov S, Alpers CE, Amore A, Barratt J, Berthoux F, Bonsib S, Bruijn JA, Cattran DC, et al: The Oxford classification of IgA nephropathy: pathology definitions, correlations, and reproducibility. Kidney Int 2009, 76(5):546-556.

19. Lee H, Yi SH, Seo MS, Hyun JN, Jeon JS, Noh H, Han DC, Hwang SD, Jin SY, Kwon $\mathrm{SH}$ : Validation of the oxford classification of IgA nephropathy: a single-center study in korean adults. Korean J Intern Med 2012, 27(3):293-300.

20. Waanders F, Vaidya VS, van Goor H, Leuvenink H, Damman K, Hamming I, Bonventre JV, Vogt L, Navis G: Effect of renin-angiotensin-aldosterone system inhibition, dietary sodium restriction, and/or diuretics on urinary kidney injury molecule 1 excretion in nondiabetic proteinuric kidney disease: a post hoc analysis of a randomized controlled trial. Am J Kidney Dis 2009, 53(1):16-25.

21. Kramer AB, van Timmeren MM, Schuurs TA, Vaidya VS, Bonventre JV, van Goor $H$, Navis G: Reduction of proteinuria in adriamycin-induced nephropathy is associated with reduction of renal kidney injury molecule (Kim-1) over time. Am J Physiol Renal Physiol 2009, 296(5):F1136-F1145.

22. Ohtake T, Oka M, Maesato K, Mano T, Ikee R, Moriya H, Kobayashi S: Pathological regression by angiotensin II type 1 receptor blockade in patients with mesangial proliferative glomerulonephritis. Hypertens Res 2008, 31(3):387-394.

23. Adamczak M, Gross ML, Krtil J, Koch A, Tyralla K, Amann K, Ritz E: Reversal of glomerulosclerosis after high-dose enalapril treatment in subtotally nephrectomized rats. J Am Soc Nephrol 2003, 14(11):2833-2842.

24. Fujihara CK, Velho M, Malheiros DM, Zatz R: An extremely high dose of losartan affords superior renoprotection in the remnant model. Kidney Int 2005, 67(5):1913-1924.

25. Wong MG, Suzuki Y, Tanifuji C, Akiba H, Okumura K, Sugaya T, Yamamoto T, Horikoshi S, Tan SY, Pollock C, et al: Peritubular ischemia contributes more 
to tubular damage than proteinuria in immune-mediated glomerulonephritis. J Am Soc Nephrol 2008, 19(2):290-297.

26. de Borst MH, van Timmeren MM, Vaidya VS, de Boer RA, van Dalen MB, Kramer AB, Schuurs TA, Bonventre JV, Navis G, van Goor H: Induction of kidney injury molecule-1 in homozygous Ren2 rats is attenuated by blockade of the renin-angiotensin system or p38 MAP kinase. Am J Physiol Renal Physiol 2007, 292(1):F313-F320.

27. Zoja C, Donadelli R, Colleoni S, Figliuzzi M, Bonazzola S, Morigi M, Remuzzi G: Protein overload stimulates RANTES production by proximal tubular cells depending on NF-kappa B activation. Kidney Int 1998, 53(6):1608-1615.

28. Ichimura T, Bonventre JV, Bailly V, Wei H, Hession CA, Cate RL, Sanicola M: Kidney injury molecule-1 (KIM-1), a putative epithelial cell adhesion molecule containing a novel immunoglobulin domain, is up-regulated in renal cells after injury. J Biol Chem 1998, 273(7):4135-4142.

29. Ichimura T, Hung CC, Yang SA, Stevens JL, Bonventre JV: Kidney injury molecule-1: a tissue and urinary biomarker for nephrotoxicant-induced renal injury. Am J Physiol Renal Physiol 2004, 286(3):F552-F563.

30. Donadio JV, Bergstralh EJ, Grande JP, Rademcher DM: Proteinuria patterns and their association with subsequent end-stage renal disease in IgA nephropathy. Nephrol Dial Transplant Offic Publ Eur Dial Transpl Assoc Eur Renal Assoc 2002, 17(7):1197-1203.

31. Reich HN, Troyanov S, Scholey JW, Cattran DC: Remission of proteinuria improves prognosis in IgA nephropathy. J Am Soc Nephrol 2007, 18(12):3177-3183.

32. Kuehn EW, Park KM, Somlo S, Bonventre JV: Kidney injury molecule-1 expression in murine polycystic kidney disease. Am J Physiol Renal Physiol 2002, 283(6):F1326-F1336.

doi:10.1186/1471-2369-14-139

Cite this article as: Seo et al:: Effect of treatment on urinary kidney injury molecule-1 in IgA nephropathy. BMC Nephrology 2013 14:139.

\section{Submit your next manuscript to BioMed Central and take full advantage of:}

- Convenient online submission

- Thorough peer review

- No space constraints or color figure charges

- Immediate publication on acceptance

- Inclusion in PubMed, CAS, Scopus and Google Scholar

- Research which is freely available for redistribution 